\title{
Mutual growth-promoting effect between Bifidobacterium bifidum WBBI03 and Listeria monocytogenes CMCC 54001
}

\author{
Dong Yang, ${ }^{*}$ Xiaoli Wu, $†$ Xiaomin Yu, ${ }^{,}$Lihua He, ${ }^{*}$ Nagendra P. Shah, $\ddagger^{1}$ and Feng $\mathrm{Xu}^{* 1}$ \\ *State Key Laboratory of Food Science and Technology, Nanchang University, Nanchang, Jiangxi, 330047, P. R. China \\ †Jiangxi University of Traditional Chinese Medicine, Nanchang, Jiangxi, 330004, P. R. China \\ łFood and Nutritional Science, School of Biological Science, The University of Hong Kong, Pokfulam Road, Hong Kong, 999077 , China
}

\begin{abstract}
In this study, Bifidobacterium bifidum WBBI03 and Listeria monocytogenes CMCC 54001 were selected to detect the changes in their growth pattern after mutual interaction between them. The proteomic changes after the interaction between the 2 bacteria were detected by the isobaric tags for relative and absolute quantitation method. The proteins related to the biosynthesis and cell reproduction were selected, and their changes at the transcriptional level were monitored by fluorescent quantitative PCR. Also, 3 other types of probiotic organisms and opportunistic pathogens were used to verify the results mentioned above. The results showed that growing the 2 organisms together could promote the growth of each other, resulting in earlier entry into the logarithmic phase. The results also showed that the expression of these proteins mostly tended to be upregulated at the translational and transcriptional level. The increase in the expression of these proteins might help promote the growth and reproduction of $B$. bifidum WBBI03 and L. monocytogenes CMCC 54001. One aspect of the biological significance of their presence in the normal intestine may be that the opportunistic pathogens promote the growth of the probiotics. Key words: mutual interaction, Listeria monocytogenes, Bifidobacterium bifidum, isobaric tags for relative and absolute quantitation
\end{abstract}

\section{INTRODUCTION}

Food poisoning caused by pathogenic microorganism has been commonly reported in both developed and developing countries (Le Loir et al., 2003; Chiang et al., 2012; Zarei et al., 2012; Yang et al., 2013) and the incidence of foodborne infections has increased signifi-

Received August 1, 2016.

Accepted January 16, 2017

${ }^{1}$ Corresponding authors: ziwu211@126.com and npshah@hku.hk cantly around the world in recent years (Peng et al., 2015; Hald et al., 2016). With its rich nutrient contents, milk is not only a natural medium for lactic acid bacterial growth, but also an ideal medium for the growth of opportunistic pathogens (Dobranić et al., 2015). The hazards associated with foodborne pathogens in milk and dairy products are expanding each year (Oliver et al., 2005; Claeys et al., 2013). Foodborne diseases are closely linked with the intestinal system (Manges and Johnson, 2012; Braden and Tauxe, 2013), which is the body's largest, most complicated micro-ecosystem, where various amounts and types of bacteria exist (Eckburg et al., 2005). As a result of the antagonistic and symbiotic relationship between different bacteria, as well as the interaction between microorganisms and the host, the balance of the gastrointestinal micro-ecosystem is very important in the prevention of intestinal disorders and pathogenic bacteria infections (Liévin-Le Moal and Servin, 2014; Martín et al., 2014). Once the relationship is disturbed, dysbiosis may occur, causing intestinal diseases, such as diarrhea and diseases of other organs (Dethlefsen et al., 2007).

At present, the existing literature studying the interaction between probiotic organisms and pathogenic bacteria support the idea that probiotic organisms pose effects on pathogenic bacteria through competing for adhesion sites (Salminen et al., 2010), aggregating with pathogenic bacteria and producing metabolites to inhibit pathogenic bacteria (Gagnon et al., 2011). However, the opportunistic pathogens that exist in healthy human intestine do not disappear because of the presence of intestinal probiotic organisms, indicating that some other interactions besides antagonism might exist between probiotic organisms and pathogenic bacteria (Derrien and van Hylckama Vlieg, 2015). Hence, we still cannot clearly explain the biological significance of the opportunistic pathogens that colonize healthy human intestine.

Listeria monocytogenes is one of the few harmful bacteria among Listeria species (Gaillard et al., 1991). This organism is a zoonotic pathogen widely found in 
nature that causes serious invasive diseases in human and animals, including abortion, sepsis, and meningitis (Allerberger and Wagner, 2010; Feehily et al., 2013). It can spread between human and animals through contaminated food. Although asymptomatic fecal carriage of this organism occurs in approximately $3 \%$ of healthy humans, the prevalence may be up to $26 \%$ in highrisk groups (Grif et al., 2003). However, healthy people rarely develop symptoms of bacteremia caused by $L$. monocytogenes, unless they are suffering from gastritis or have eaten severely contaminated food. Even when exposed to the pathogens, only 5 to $10 \%$ of exposed individuals develop symptoms (Sim et al., 2002). Therefore, L. monocytogenes is a typical opportunistic pathogen.

Bifidobacterium can also be commonly found in human intestine (Schell et al., 2002). Bifidobacterium bifidum is a probiotic organism that has a positive effect on gastrointestinal symptoms (Minelli et al., 2009) and immune modulation (Medici et al., 2004). Many studies have verified that Bifidobacterium plays an important physiological role in many aspects, including regulating the intestinal micro-ecological balance (Gibson and Wang, 1994; Macfarlane and Cummings, 1999), inhibiting the invasion of pathogenic bacteria (Bernet et al., 1993; Servin and Coconnier, 2003), and having anti-tumor (Lee et al., 2004), anti-mutation (Li and Zhang, 2006), and anti-aging (Xu et al., 2011) properties. Recognized as a type of probiotic organism, Bifidobacterium has become a hot spot of research in the current nutrition and health industries. Bifidobacterium has been developed as a core aspect of microecology and has been gradually applied in the fields of medicine and food.

In this study, we investigated the growth of $B$. bifidum and L. monocytogenes after coculture interaction in PBS. By using the isobaric tags for relative and absolute quantitation (iTRAQ), we detected proteomic changes in the 2 bacteria during the process of interaction in an attempt to discover the possible molecular mechanisms. Reverse-transcription quantitative PCR (RT-qPCR) was used to investigate the changes in the related genes at the transcriptional level. It is expected that our findings will provide a useful reference for properly exploring and assessing the biological significance of the presence of opportunistic pathogens.

\section{MATERIALS AND METHODS}

\section{Cultivation and Preparation of Strains}

Bifidobacterium bifidum WBBI03 was provided by the Jiangxi-Oai Joint Research Institute, Nanchang
University, Nanchang, P. R. China. Listeria monocytogenes CMCC 54001 was provided by the National Center for Medical Culture Collection (CMCC) of China. A single colony of L. monocytogenes was subcultured aerobically in brain heart infusion (BHI) broth (Beijing Solarbio Science and Technology Co. Ltd., Beijing, China) under shaking (180 rpm) at $37^{\circ} \mathrm{C}$ for $18 \mathrm{~h}$. Bifidobacterium bifidum was cultured under anaerobic conditions in de Man, Rogosa, and Sharpe (MRS) broth (Difco Laboratories, Detroit, MI) containing $0.05 \%$ L-cysteine (Beijing Solarbio Science and Technology Co. Ltd.) at $37^{\circ} \mathrm{C}$ for $24 \mathrm{~h}$. The bacterial suspension was centrifuged at $8,000 \times g$ for $10 \mathrm{~min}$ at $4^{\circ} \mathrm{C}$. After that, the bacteria were washed 3 times with PBS and resuspended in PBS. The cell concentration was adjusted to approximately $10^{9} \mathrm{cfu} / \mathrm{mL}$ according to the corresponding curve of absorbance and the viable count.

\section{Co-Incubation and Viable Count}

Both bacteria at $10^{9} \mathrm{cfu} / \mathrm{mL}$ were suspended in sterile PBS. Aliquots $(5 \mathrm{~mL})$ of both organisms were mixed thoroughly, left undisturbed at $37^{\circ} \mathrm{C}$ for $2 \mathrm{~h}$, and sampled before and after incubation. According to the previous methods, lithium propionate MRS was used for B. bifidum WBBI03 (Vinderola and Reinheimer, 1999), and L. monocytogenes CMCC 54001 cannot grow in a lithium propionate MRS agar plate under an anaerobic environment. Modified Oxford agar (Park et al., 2014) was used for L. monocytogenes to perform the viable count, which was repeated 3 times.

\section{Detecting Growth Promotion Between B. bifidum WBBI03 and L. monocytogenes CMCC 54001}

Experiment of Different Strain Concentrations on Growth Promotion. The ratio of B. bifidum WBBI03 to L. monocytogenes CMCC 54001 was kept at 1:10,1:1, and 10:1, respectively, by keeping the former at $10^{8} \mathrm{cfu} / \mathrm{mL}$ and diluting the latter (Figure 1). These samples were incubated at $37^{\circ} \mathrm{C}$ for $2 \mathrm{~h}$, as before. Meanwhile, the single bacterial suspension of $B$. bifidum WBBI03 at $10^{8} \mathrm{cfu} / \mathrm{mL}$ was used as an individual group (Figure 1). After incubation, the bacteria were inoculated at the level of $1 \%$ into the MRS medium and incubated anaerobically at $37^{\circ} \mathrm{C}$. It was sampled at 0,2 , $3,5,8,16$, and $24 \mathrm{~h}$, respectively, and the viable count of $B$. bifidum WBBI03 was enumerated.

Bacterial suspensions of B. bifidum WBBI03 at $10^{8}$ $\mathrm{cfu} / \mathrm{mL}$ were used as the separate incubation group, and those added with $B$. bifidum WBBI03 with final concentrations of $10^{7}, 10^{8}$, and $10^{9} \mathrm{cfu} / \mathrm{mL}$ were used 


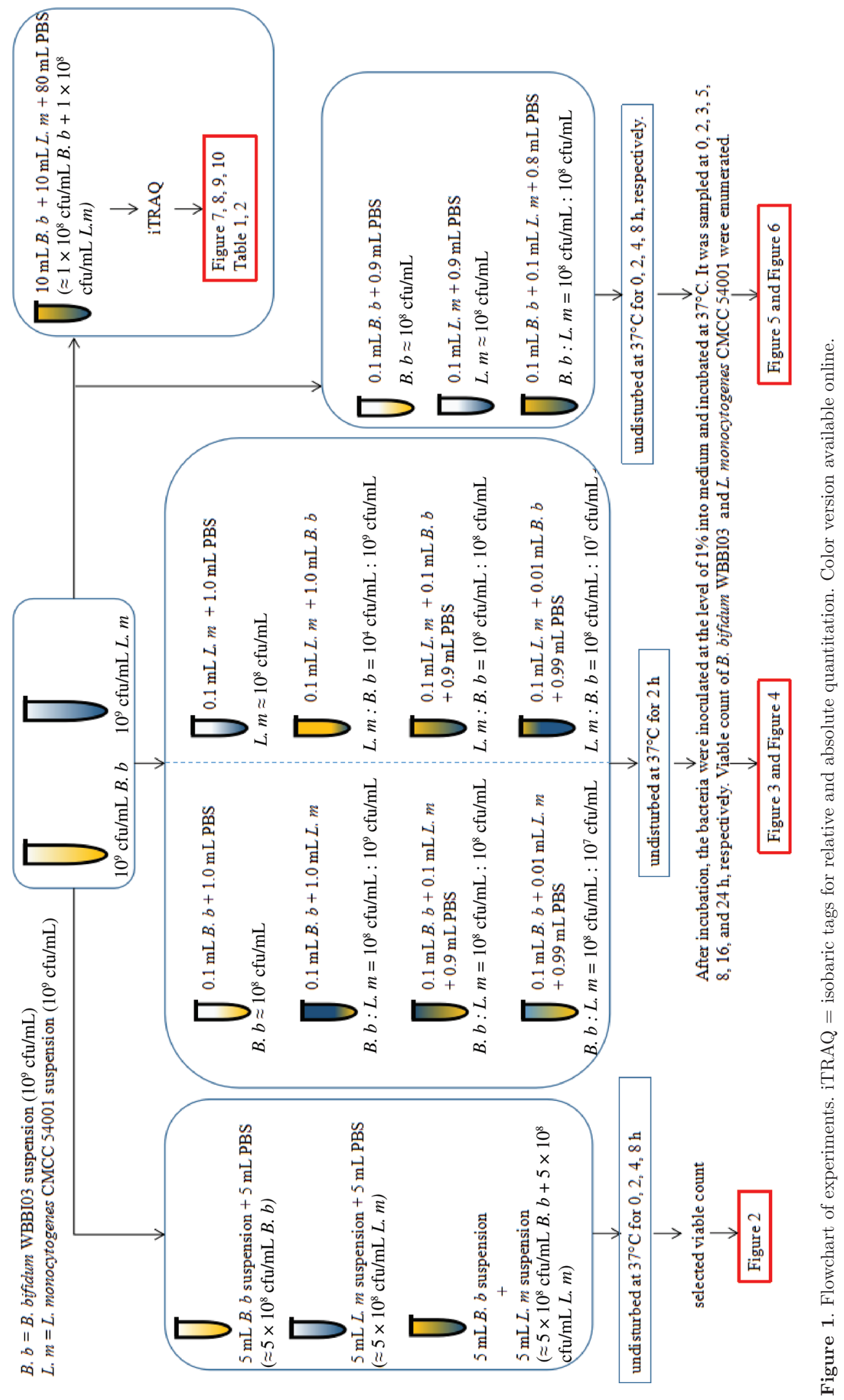


as the co-incubation group (Figure 1). Meanwhile, the single bacterial suspension of $L$. monocytogenes CMCC 54001 at $10^{8} \mathrm{cfu} / \mathrm{mL}$ was used as an individual group. After incubation, the bacteria were inoculated at the level of $1 \%$ into the BHI medium and incubated under shaking at $37^{\circ} \mathrm{C}$. It was sampled at $0,2,3,5,8,16$, and $24 \mathrm{~h}$, and the viable count of $L$. monocytogenes CMCC 54001 was enumerated.

Experiment of Different Co-Incubation Time in PBS on Growth Promotion. The $10^{8} \mathrm{cfu} / \mathrm{mL}$ suspensions of B. bifidum WBBI03 and L. monocytogenes CMCC 54001 were mixed in equal volumes. After co-incubation at $37^{\circ} \mathrm{C}$ for 2,4 , and $8 \mathrm{~h}$, the mixed bacteria were inoculated at the level of $1 \%$ into the MRS medium at $37^{\circ} \mathrm{C}$ for $24 \mathrm{~h}$, or aerobically in BHI medium with shaking $(180 \mathrm{rpm})$ at $37^{\circ} \mathrm{C}$. Samples were taken at $0,2,3,5,8,16$, and $24 \mathrm{~h}$.

\section{Preparation of Protein Samples and Proteomic Detection by ITRAQ}

The $10^{9} \mathrm{cfu} / \mathrm{mL}$ suspensions of $B$. bifidum and $L$. monocytogenes were mixed in equal volumes. After co-incubation at $37^{\circ} \mathrm{C}$ for $2 \mathrm{~h}$, the suspension was centrifuged at $8,000 \times \mathrm{g}$ for $10 \mathrm{~min}$ at $4^{\circ} \mathrm{C}$ and $0.2 \mathrm{~g}$ of bacteria was collected and added with $500 \mu \mathrm{L}$ of protein lysate. The suspensions of the 2 bacteria were taken at the same time and incubated separately and $0.1 \mathrm{~g}$ of each of them was collected and added with 250 $\mu \mathrm{L}$ of protein lysate before resuspension. Then they were mixed as the protein samples of the separate incubation group. After ultrasound treatment for $15 \mathrm{~min}$, the samples were centrifuged at $25,000 \times g$ for $20 \mathrm{~min}$ at $4^{\circ} \mathrm{C}$. The supernatant was added with dithiothreitol at a final concentration of $10 \mathrm{~m} M$ and incubated for $1 \mathrm{~h}$ at $56^{\circ} \mathrm{C}$, for reducing and opening the disulfide bonds. Then it was added with iodoacetamide at a final concentration of $55 \mathrm{~m} M$ and kept in a dark room for 45 min, before the alkylation closing of the cysteine. An appropriate amount of cold acetone was added, and the samples were kept at $-20^{\circ} \mathrm{C}$ for $2 \mathrm{~h}$. After centrifugation at $25,000 \times g$ for $20 \mathrm{~min}$ at $4^{\circ} \mathrm{C}$, the supernatant was discarded and the precipitate was dissolved using ultrasound in $200 \mu \mathrm{L}$ of $0.5 \mathrm{M}$ tetraethyl-ammonium bromide for $15 \mathrm{~min}$. After centrifugation at 25,000 $\times$ $g$ for $20 \mathrm{~min}$ at $4^{\circ} \mathrm{C}$, the supernatant was taken. The prepared samples were sent to the Beijing Genomics Institute (Shenzhen, Guangdong, China) for iTARQ proteomic sequencing.

\section{Reverse Transcription Quantitative PCR}

Suspensions of B. bifidum WBBI03 and L. monocytogenes CMCC 54001 were mixed in equal volumes. After co-incubation and separate incubation in PBS at $37^{\circ} \mathrm{C}$ for $2,4,8 \mathrm{~h}$, respectively, total RNA was isolated from the 2 organisms using TRIzol reagent (Takara Bio, Dalian, China). Single-strand cDNA was synthesized from the total RNA using the PrimeScript RT reagent kit with gDNA Eraser for quantitative PCR (Takara Bio) according to the manufacturer's instructions.

The primers used in this study are listed in Table 1 and were designed according to the ratio of differential

Table 1. Genes and primers selected for reverse-transcription quantitative PCR

\begin{tabular}{|c|c|c|}
\hline Gene & Forward primer $\left(5^{\prime}-3^{\prime}\right)$ & Reverse primer $\left(5^{\prime}-3^{\prime}\right)$ \\
\hline \multicolumn{3}{|c|}{ Bifidobacterium bifidum WBBI03 } \\
\hline B1 (BBIF_0529) & CAAGGGCATTCAGGAGGC & AAGCACTTCGGACTCGTCG \\
\hline $\mathrm{B} 2(r p s J)$ & GCCGACCGAGAAGAACG & GTGCATCAGAGAATCCACAGC \\
\hline $\mathrm{B} 4\left(B B I F \_1401\right)$ & CTACGCCGACACGTATCTGC & CGATGTTCTCGCCTTGTCC \\
\hline B5 $(r \ln N)$ & CCACGTTATGCATCTCCAGC & GCACCTGTTCCAGAATCTCG \\
\hline $\mathrm{B} 6($ rpmC) & CGGTCAAGCACGACATCG & TTACTTCTCCTCCGACTTGGTCTC \\
\hline $\mathrm{B} 10(p d x S)$ & TCATGGACGTGACGACTCC & AGACGGCCTCCTGAATGC \\
\hline $\mathrm{B} 11\left(B B I F \_0575\right)$ & GTCACCGTCACATCCATCG & CGTCCTCGTGCTTCATCG \\
\hline purB & CCGCAATCGCATTGACC & TCGACACGCATGCGTTC \\
\hline \multicolumn{3}{|c|}{ Listeria monocytogenes CMCC 54001} \\
\hline$t s f$ & CTCTGCTTTCGGTGAATACATCC & CTTCTTCAGAAGAAACATCTTCACG \\
\hline $\operatorname{divIVA}$ & GCCGAAGAAGTGAAAGCTTCC & ACTAGCATACGTAAACGCTCACG \\
\hline $16 S \mathrm{rRNA}$ & TTTAGTTGCCAGCATTTAGTTGG & GTGTGTAGCCCAGGTCATAAGG \\
\hline
\end{tabular}




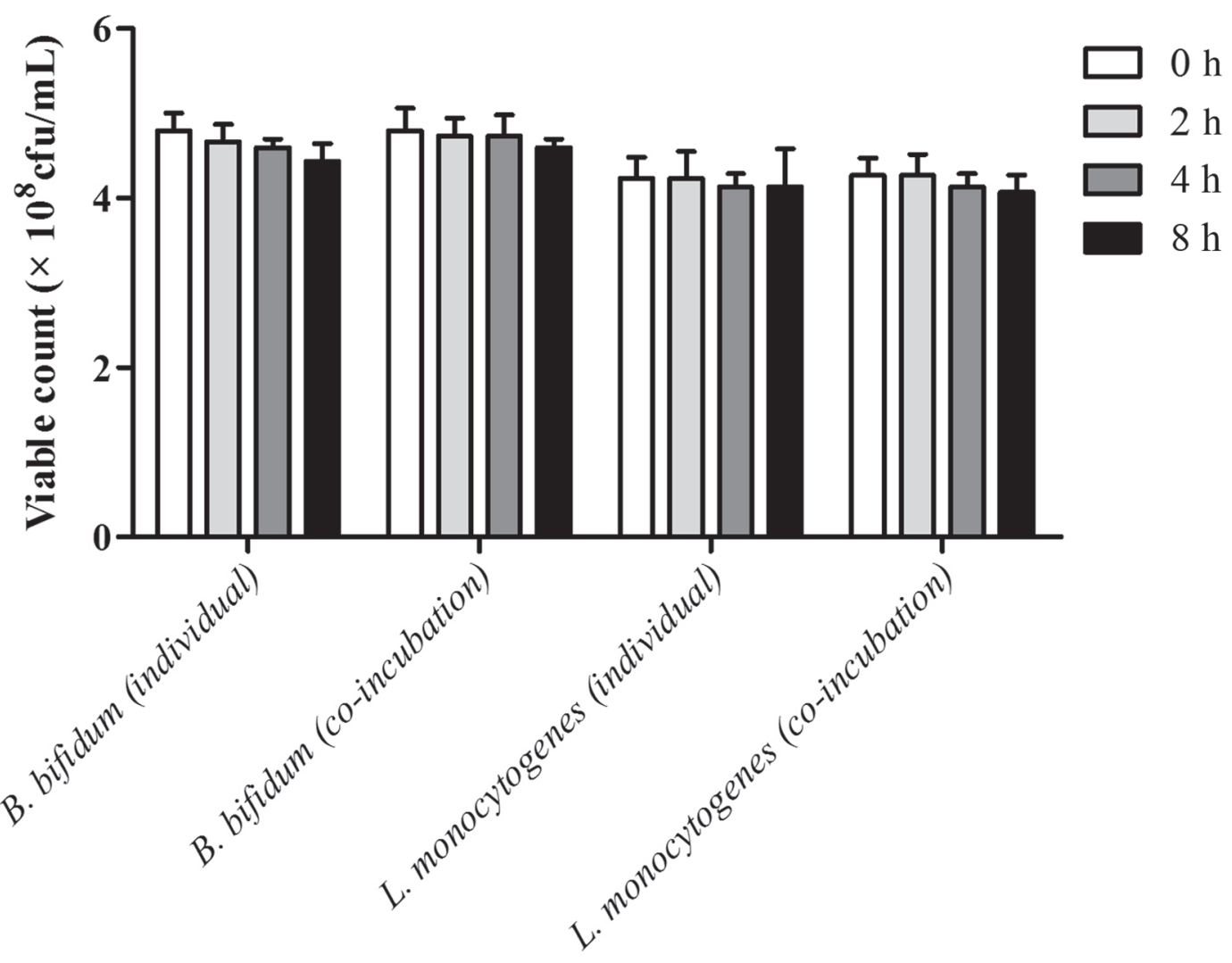

Figure 2. Changes in viable counts of Bifidobacterium bifidum WBBI03 and Listeria monocytogenes CMCC 54001 before and after incubation. White bars represent that the bacteria were sampled before incubation $(0 \mathrm{~h})$. Gray bars, dark gray bars, and black bars represent that the bacteria were individually or co-incubated in PBS for 2, 4, and $8 \mathrm{~h}$, respectively. Lithium propionate de Man, Rogosa, and Sharpe agar was used for B. bifidum WBBI03, and modified Oxford agar was used for L. monocytogenes, respectively. Error bars indicate standard deviations for triplicates.

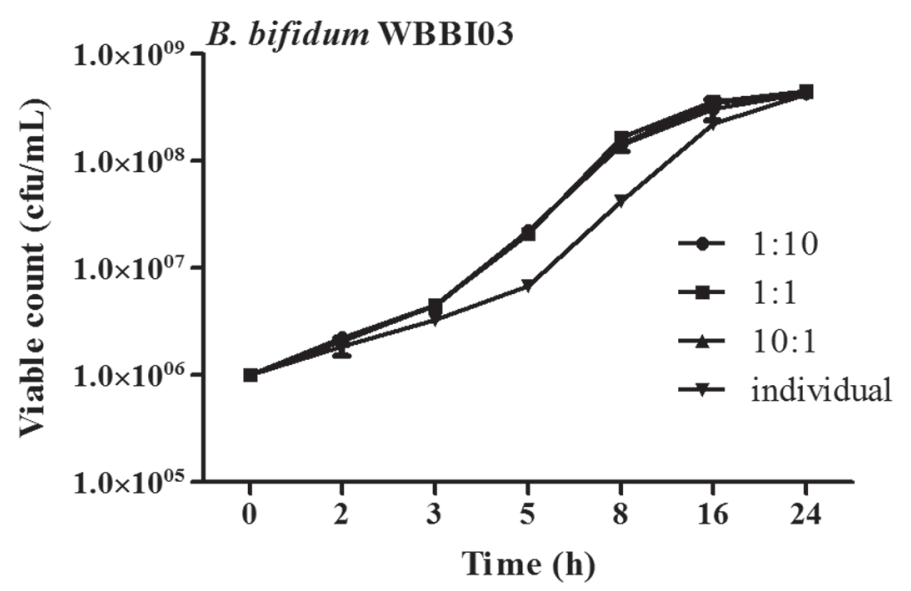

Figure 3. Viable counts of Bifidobacterium bifidum WBBI03 after the growth promotion by co-incubating with Listeria monocytogenes CMCC 54001. The bacteria were inoculated at the level of $1 \%$ into the de Man, Rogosa, and Sharpe medium and anaerobically incubated at $37^{\circ} \mathrm{C}$. It was sampled at $0,2,3,5,8,16$, and $24 \mathrm{~h}$, respectively, and the viable count of $B$. bifidum WBBI03 was performed. Error bars indicate standard deviations for triplicates. proteins and existing literature, and were synthesized by Invitrogen China (Shanghai, China) using 16S rRNA as the endogenous control for L. monocytogenes and purB as endogenous control for B. longum (Tan et al., 2012). If PCR inhibition occurred (no amplification of the internal positive control of a threshold cycle $>40$ ), the cDNA samples were diluted 2- to 30 -fold in distilled water. If false-negative results were suspected, cDNA samples were purified again (Mérault et al., 2011). The quantitative PCR was conducted with a SYBR Premix Ex Taq II (Tli RNaseH Plus, Takara Bio). Amplification and detection were carried out in 96-well plates with a 7900 HT Fast Real Time-PCR System (Applied Biosystems, Foster City, CA). The PCR was carried out in a final volume of $20 \mu \mathrm{L}$. Thermal cycler conditions were $95^{\circ} \mathrm{C}$ for $3 \mathrm{~min}$, followed by 40 cycles at $95^{\circ} \mathrm{C}$ for $5 \mathrm{~s}$, and then $60^{\circ} \mathrm{C}$ for $30 \mathrm{~s}$. Each test was performed in duplicate. Relative mRNA levels were determined by comparative critical threshold quantitative PCR (in a separate tube), as described by Applied Biosystems User Bulletin no. 2 (P/N 4303859). 


\section{Detecting the Mutual Growth-Promoting Effect Between Probiotics and Opportunistic Pathogens}

The combinations of Bifidobacterium longum WBLO01 and Escherichia coli O157:H7, Lactobacillus rhamnosus GG and Enterobacter sakazakii ATCC 29544, and Lactobacillus plantarum ATCC 8014 and Staphylococcus aureus CMCC 26003 were selected to represent the interaction between probiotics and opportunistic pathogens. According to the method of $B$. bifidum WBBI03 and L. monocytogenes CMCC 54001, co-incubation at 1:1 (equal amount) was carried out. After comparison of the bacterial amount before and after incubation, the probiotics were inoculated at the level of $1 \%$ into the MRS medium, and the opportunistic pathogens into the BHI medium. Samples were taken at $5 \mathrm{~h}$, and the changes in the viable counts were detected by comparing with the separate incubation group.

\section{Statistical Analysis}

Tests were carried out in triplicate for all experiments. All data were expressed as means \pm standard deviation of 3 parallel tests. The SPSS version 14.0 software was used for statistical analyses (SPSS Inc., Chicago, IL) by means of independent one-way ANOVA tests. Statistical analysis on the figures was carried out by using GraphPad Prism 5.0 software (GraphPad Software Inc., La Jolla, CA).

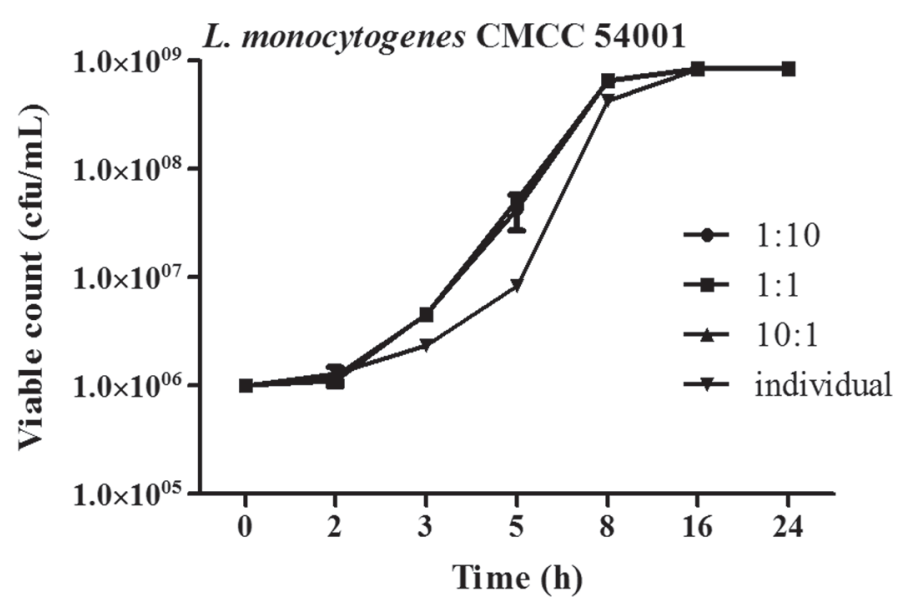

Figure 4. Viable counts of Listeria monocytogenes CMCC 54001 after the growth promotion by co-incubating with Bifidobacterium bifidum WBBI03. The bacteria were inoculated at the level of $1 \%$ into the brain heart infusion medium and probiotic culture at $37^{\circ} \mathrm{C}$. It was sampled at $0,2,3,5,8,16$, and $24 \mathrm{~h}$, respectively, and the viable count of L. monocytogenes CMCC 54001 was performed. Error bars indicate standard deviations for triplicates.

\section{RESULTS}

\section{Changes in the Bacterial Counts When Grown Individually and After Co-Incubation}

As shown in Figure 2, when the numbers of B. bifidum WBBI03 and L. monocytogenes CMCC 54001 were inoculated alone or at the 1:1 ratio, representing $4.8 \times$ $10^{8}$ and $4.2 \times 10^{8} \mathrm{cfu} / \mathrm{mL}$, respectively, no significant change $(P<0.05)$ in viable counts occurred during the $8 \mathrm{~h}$ incubation in the PBS buffer. This suggested that, in the PBS buffer, the numbers of the 2 bacteria would not change. In the separate incubation group, the bacteria number also did not change significantly between before and after incubation buffer in PBS at 2, 4 , and $8 \mathrm{~h}$ of incubation.

\section{Effect of Different L. monocytogenes CMCC 54001 Bacterial Counts on Growth Promotion of B. Bifidum WBBI03}

The co-incubation group was compared with the individual incubation group. As shown in Figure 3, the bacterial numbers started to increase from $2 \mathrm{~h}$. It was still higher than the individual incubation group at 16 $\mathrm{h}$, but after the stable phase at $24 \mathrm{~h}$, the number became closer, suggesting that L. monocytogenes CMCC 54001 could significantly promote the growth of $B$. bifidum WBBI03 $(P<0.05)$. Little difference was observed in the number of $B$. bifidum WBBI03 incubated with $L$. monocytogenes CMCC 54001 of various concentrations, suggesting that this growth-promoting effect was not affected by the number of $L$. monocytogenes CMCC 54001 within a certain density range.

\section{Effect of Different B. bifidum WBBI03 Bacterial Numbers on the Growth Promotion of L. monocytogenes CMCC 54001}

After the co-incubation, the strains were inoculated into the medium. As shown in Figure 4, the growth of L. monocytogenes CMCC 54001 was similar to that of B. bifidum WBBI03. From 3 to $8 \mathrm{~h}$ in the early phase, the bacterial numbers in the co-incubation group increased significantly more than those in the individual incubation group. But after the stable phase at $8 \mathrm{~h}$, the numbers became closer, suggesting that $B$. bifidum WBBI03 could promote the growth of L. monocytogenes CMCC 54001. Similarly, the density of B. bifidum WBBI03 made no significant difference in this growthpromoting effect. 
A

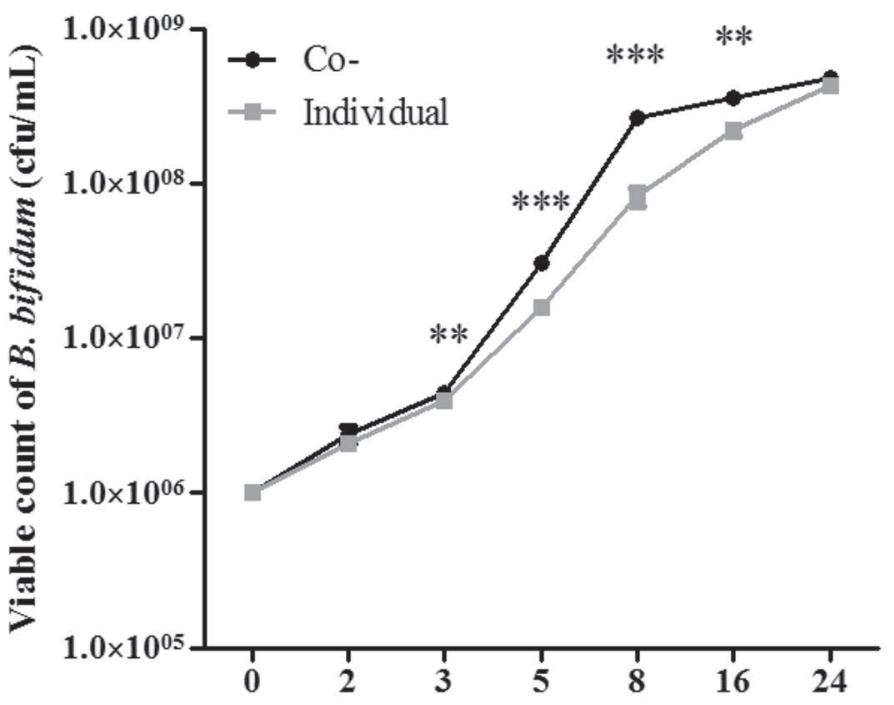

C

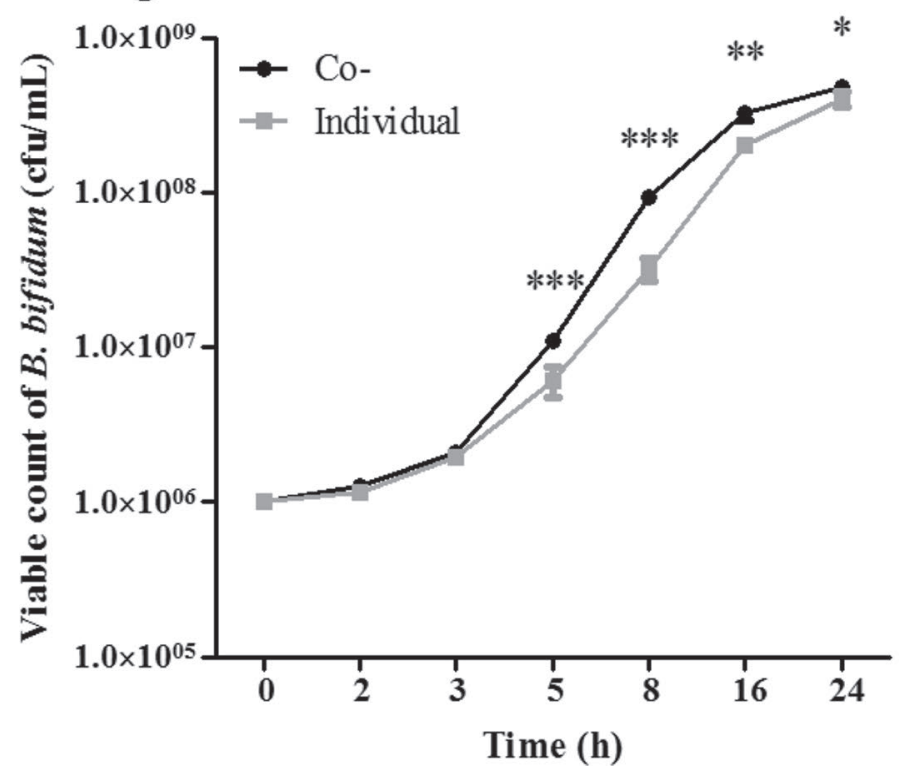

B

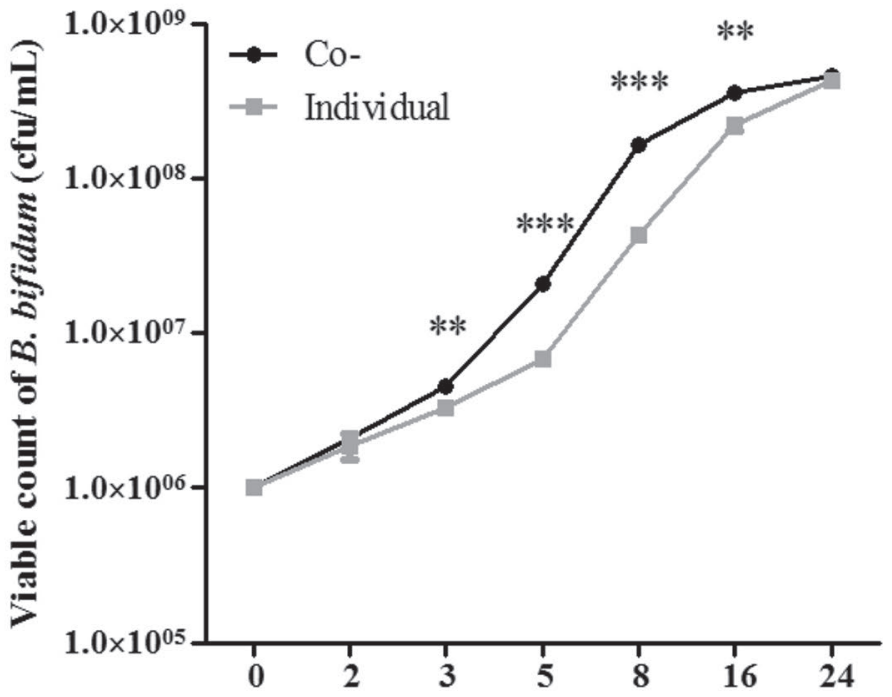

D

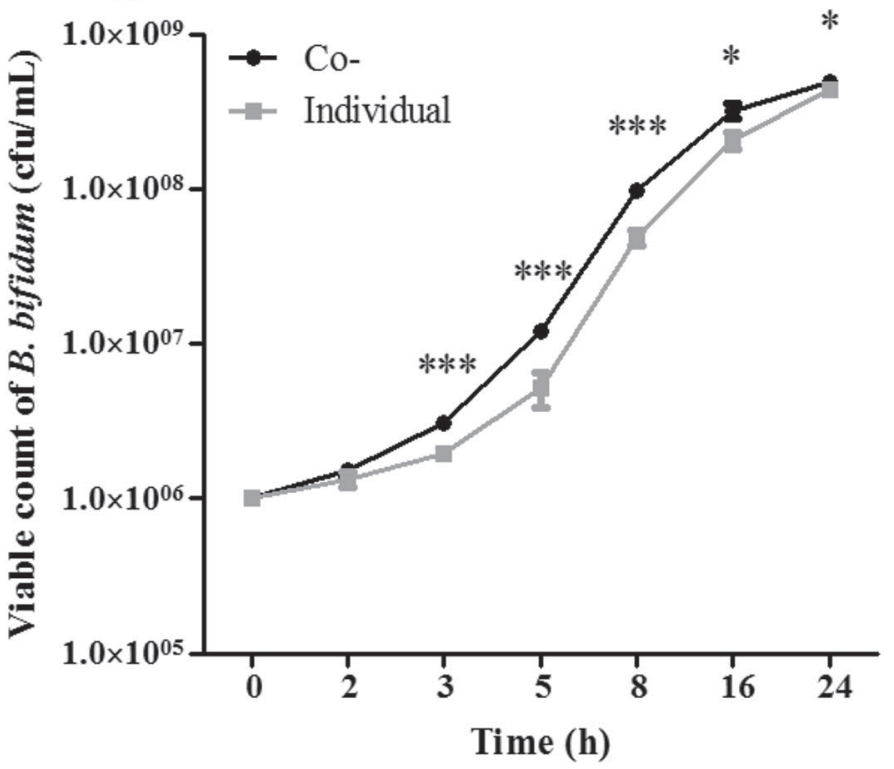

Figure 5. The growth ratios of Bifidobacterium bifidum WBBI03 after individual and co-incubation in PBS at $0,2,4$, and 8 h were detected. (A) After individual and co-incubation in PBS at $0 \mathrm{~h},(\mathrm{~B})$ after individual and co-incubation in PBS at $2 \mathrm{~h}$, (C) after individual and coincubation in PBS at $4 \mathrm{~h}$, and (D) after individual and co-incubation in PBS at $8 \mathrm{~h}$. Data are presented as the mean values, and the error bars represent the standard deviations of triplicates. ${ }^{*} P<0.05$; ${ }^{*} P<0.01 ;{ }^{*} * * P<0.001$ : significant difference compared with the individual group.

\section{Effect of Different Co-Incubation Time in PBS on Growth Promotion}

The growth curve of $B$. bifidum WBBI03 after coincubation or individually grown in PBS $0 \mathrm{~h}$ (Figure $5 \mathrm{~A}$ ), $2 \mathrm{~h}$ (Figure 5B), $4 \mathrm{~h}$ (Figure 5C), and $8 \mathrm{~h}$ (Figure 5D) is shown in Figure 5. After co-incubation and individually grown in PBS at 0 and $2 \mathrm{~h}$, the $B$. bifidum
WBBI03 numbers increased significantly $(P<0.01)$ this was much higher than that of the individual incubation group from 3 to $16 \mathrm{~h}$. Similarly, for $4 \mathrm{~h}$ (Figure 5C) and $8 \mathrm{~h}$ (Figure 5D), B. bifidum WBBI03 numbers also increased significantly $(P<0.05)$ and were higher than those separate incubation groups from 5 to 24 $\mathrm{h}$ and 3 to $24 \mathrm{~h}$, respectively. After co-incubation in PBS 0, 2, 4, and $8 \mathrm{~h}$, the growth-promoting effect in 
B. bifidum WBBI03 still appeared. The number of $B$. bifidum WBBI03 in 5 and 8 h had the highly significant increase in each of the different treatment groups.

Correspondingly, the growth curves of L. monocytogenes CMCC 54001 after co-incubation and individually grown in PBS at $0 \mathrm{~h}$ (Figure 6A), $2 \mathrm{~h}$ (Figure 6B), $4 \mathrm{~h}$ (Figure 6C), and $8 \mathrm{~h}$ (Figure 6D) are shown in Figure 6. Similar to the results of B. bifidum WBBI03, after co-incubation in PBS at $0,2,4$, and $8 \mathrm{~h}$, the ef- fect of growth-promotion in L. monocytogenes CMCC 54001 still occurred. The growth-promoting phenomenon after co-incubation in PBS at $0 \mathrm{~h}$ presented later than the other groups. After co-incubation in PBS at 2 $\mathrm{h}$, the effect of growth promotion in L. monocytogenes CMCC 54001 was highly significant $(P<0.001)$ from 3 to $8 \mathrm{~h}$. Moreover, the appearance of growth-promotion of L. monocytogenes CMCC 54001 was delayed due to time of co-incubation in PBS.
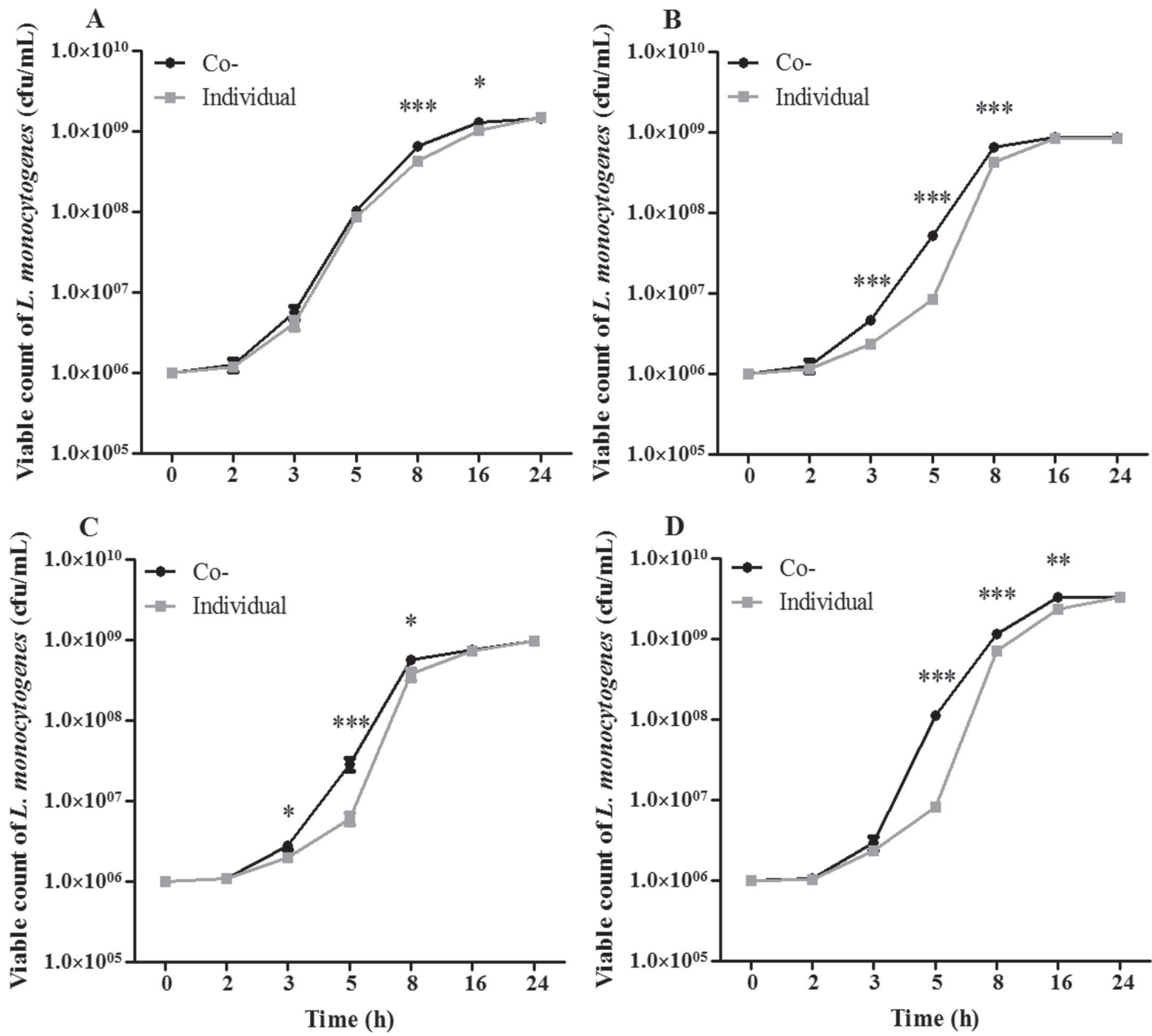

Figure 6. The growth ratios of Listeria monocytogenes CMCC 54001 after individual and co-incubation in PBS at 0 , 2, 4, and $8 \mathrm{~h}$ were detected. (A) After individual and co-incubation in PBS at $0 \mathrm{~h},(\mathrm{~B})$ after individual and co-incubation in PBS at $2 \mathrm{~h},(\mathrm{C})$ after individual and co-incubation in PBS at $4 \mathrm{~h}$, and (D) after individual and co-incubation in PBS at $8 \mathrm{~h}$. Data are presented as the mean values, and the error bars represent the standard deviations of triplicates. ${ }^{*} P<0.05 ;{ }^{* *} P<0.01 ;{ }^{* *} P<0.001$ : significant difference compared with the individual group. 


\section{Proteomics Analysis to Identify Changes in Expression of Bacterial Growth- Related Proteins}

To further understand the molecular mechanisms of interaction and to find the differential proteins that were expressed, we conducted the iTRAQ proteomic sequencing on B. bifidum WBBI03 and L. monocytogenes CMCC 54001 in the co-incubation and the individual incubation groups. A total of 1,328 proteins were identified and the distribution is shown in Figure 7A. The

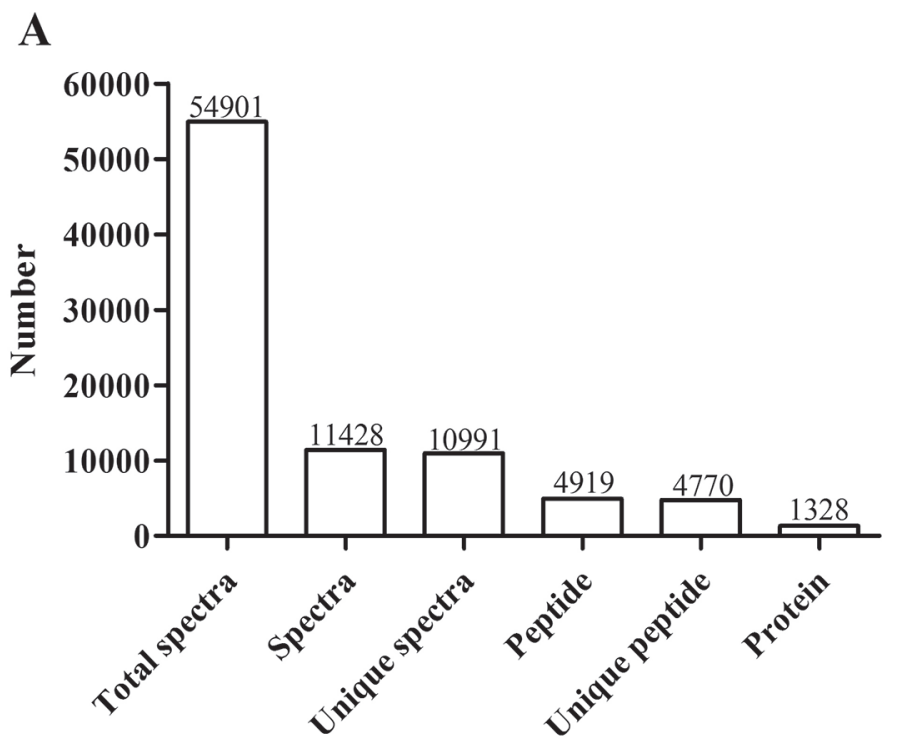

B

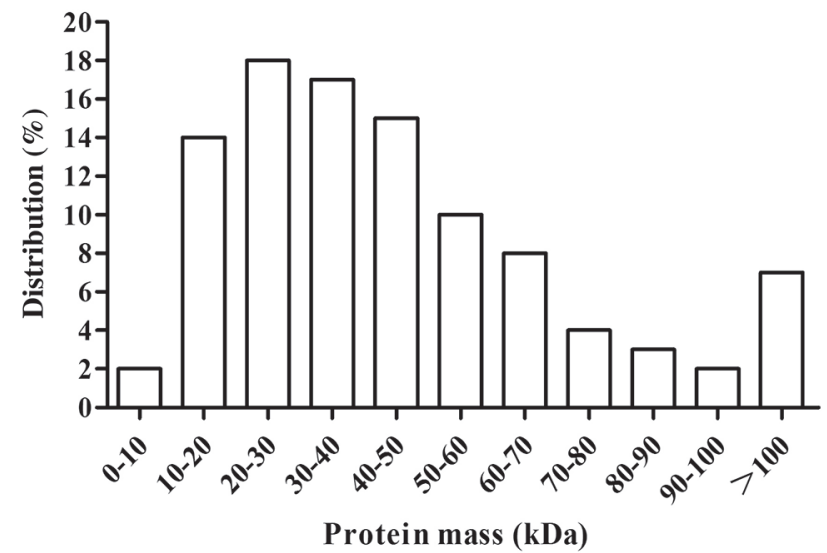

Figure 7. Protein identification. (A) Basic information statistics; xaxis: identified category, y-axis: number. Total spectra: the total number of secondary spectra; spectra: matched number of spectra; unique spectra: the spectra number of matched unique peptides (unique peptides of the samples that matched the spectra); peptide: the number of identified peptides; unique peptide: the number of unique peptide sequences; and protein: the number of identified proteins. (B) Protein mass distribution; x-axis: identified protein molecular mass (kDa), yaxis: the percentage of identified proteins. molecular weight of most identified proteins was 10 to $70 \mathrm{kDa}$, only $2 \%$ less than $10 \mathrm{kDa}$, and about $7 \%$ more than $100 \mathrm{kDa}$, as shown in the Figure 7B. Currently, as the bioinformatics have been well developed, functional annotation could be available for most identified proteins, and only the functions of 83 proteins remained unknown (Figure 8). The Gene Ontology entries involved in the 3 ontologies (cellular component, biological process, and molecular function) are summarized in Figure 9.

When the abundance ratio, that is, the difference multiple of the protein was greater than 1.2 , and the $P$-value of the statistical test was less than 0.05 , the protein could be regarded as the differential protein between the co-incubation and the individual incubation groups. The logarithm of the difference multiple of each protein to base 2 was distributed as shown in Figure 10. The expressions of 53 proteins were upregulated, on the positive half of the $\mathrm{x}$-axis, and the expressions of 63 proteins were downregulated, on the negative half of the $\mathrm{x}$-axis.

Among these differential proteins, 11 of $B$. bifidum WBBI03 and 8 of L. monocytogenes CMCC 54001 were involved in the synthesis of proteins and nucleic acids, as well as cell proliferation, and their expressions were upregulated, as listed in Table 2.

\section{Fluorescent Quantitative Detection of Changes in Bacterial Growth-Related Gene Transcription}

According to the results of proteomic sequencing, primers were designed to detect the changes after incubation in PBS at $37^{\circ} \mathrm{C}$ for 2,4 , and $8 \mathrm{~h}$ at the transcription level via fluorescent RT-qPCR. Figure 11 shows that most genes increased their synthesis of RNA on the transcriptional level, basically consistent with the results of proteomic sequencing. The only difference was that the pyridoxine biosynthesis enzyme transcription of Bifidobacterium was downregulated. Interestingly, the related transcriptional level of $L$. monocytogenes CMCC 54001 of 4-h group increased substantially more than those of the 2- and 8-h groups. The RT-qPCR results of all 7 genes of $L$. monocytogenes and 10 out of 11 genes of Bifidobacterium confirmed the results of proteomics.

\section{Mutual Growth-Promoting Effect Between Probiotics and Opportunistic Pathogens}

In addition, the combinations of B. longum WBLO01 and E. coli O157:H7, L. rhamnosus GG and E. sakazakii ATCC 29544, and L. plantarum ATCC 8014 and S. aureus CMCC 26003 were selected and sampled in $5 \mathrm{~h}$. The changes in the bacterial numbers were com- 
pared before and after incubation. As shown in Figure 12 , these 6 bacteria numbers were significantly more than the bacteria numbers in the individual incubation group after incubation, with various rates of increase ranging from 4 to $300 \%$. All of them reflected the mutual growth-promoting effect, which might be a common phenomenon after interaction between probiotics and opportunistic pathogens.

\section{DISCUSSION}

The 6 main relationships among species in an ecosystem include cooperation, commensalism, symbiosis, parasitism, predation, and competition. However, several studies pertaining to the relationship between probiotics and opportunistic pathogenic bacteria mainly focus on the antagonism of probiotics against pathogenic bacteria (Bernet et al., 1993; Servin and Coconnier, 2003), but a few reports are available about other relationships. For the first time, this paper reveals a possible symbiotic relationship between probiotics and pathogenic bacteria.

No study has been done on the proteomic analysis of the interactions between probiotics and pathogenic bacteria. In this paper, iTRAQ was employed to analyze the differential proteins induced by the interactions between B. bifidum WBBI03 and L. monocytogenes CMCC 54001. The results showed increased amounts of the enzymes involved in the biosynthesis of proteins and nucleic acids, including ribosomal protein, transfer RNA glutamyl transferase enzymes, and translation elongation factor. All of these are the components of the protein translation system, and the increases of these components facilitate the translation of proteins.

In addition, B. bifidum WBBI03 and L. monocytogenes CMCC 54001 shared a functionally similar protein (B7 of B. bifidum WBBI03 and divIVA of $L$. monocytogenes CMCC 54001), the cell division initiation protein. In the previous literature, it was called divIVA and considered to be a conservative protein

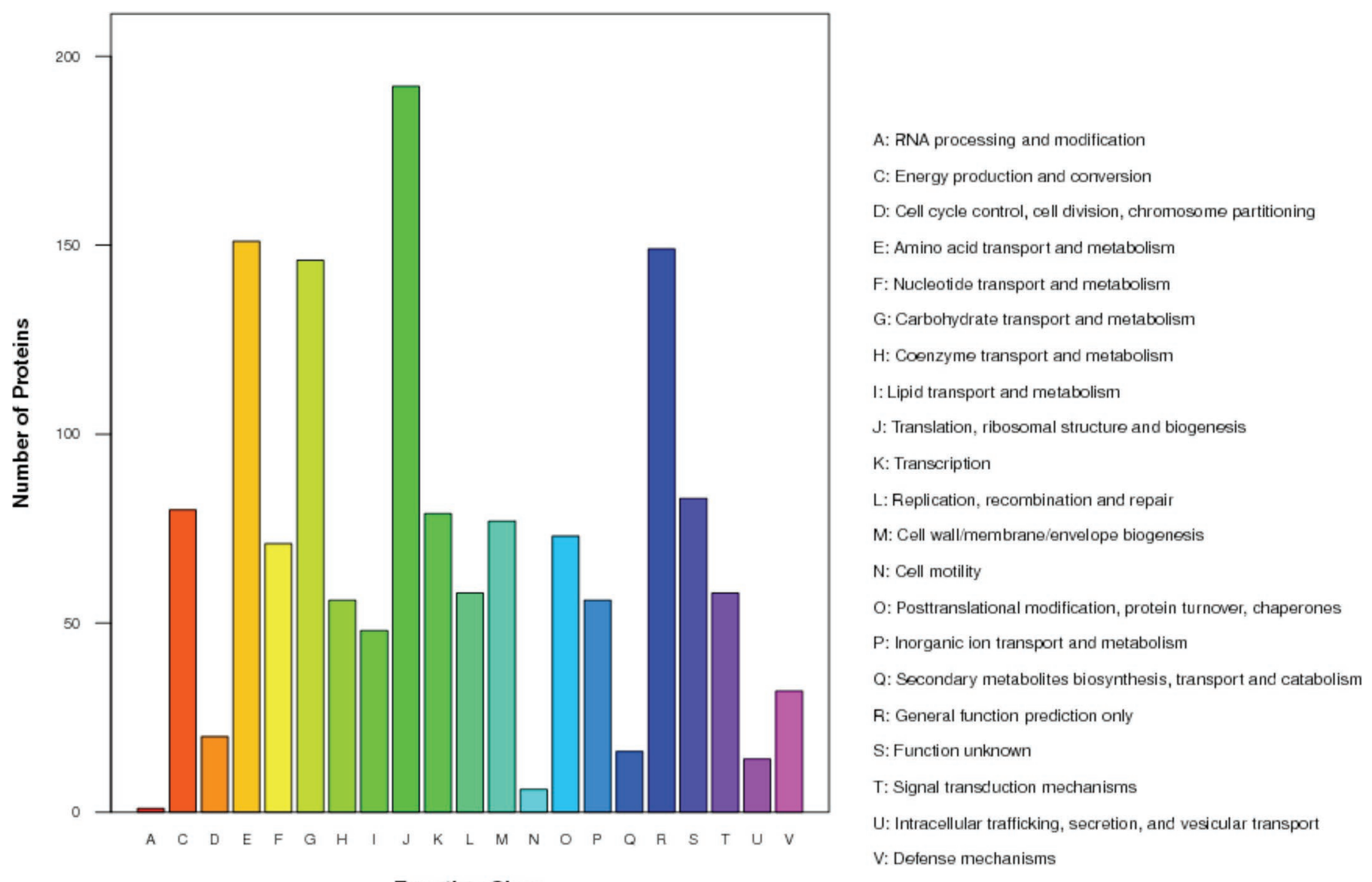

Function Class

Figure 8. Cluster of orthologous groups of proteins (COG) function classification of cell sequence; $x$-axis: COG classification entry, y-axis: the number of the corresponding protein by functional classification. Color version available online. 
involved in cell division positioning, peptidoglycan synthesis, and sporulation in the gram-positive bacteria. Halbedel et al. (2012) found that the absence of
divIVA in $L$. monocytogenes could reduce the protein expression of p60 and MurA, thereby affecting the cell division and interfering with cell reproduction. They

A

\section{cellular component}

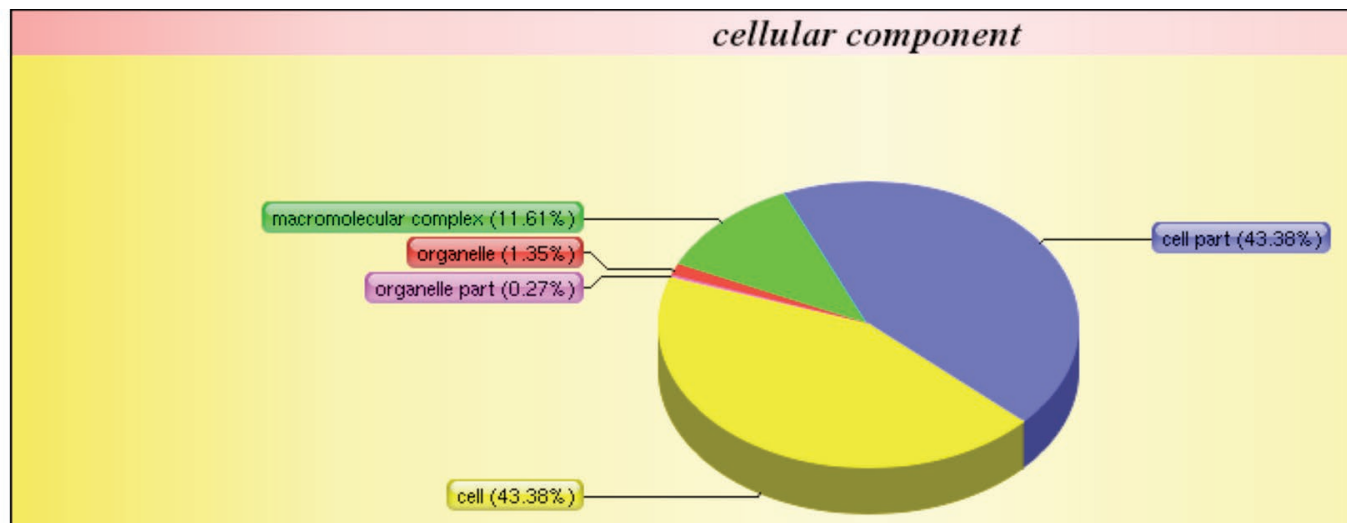

molecular function

B

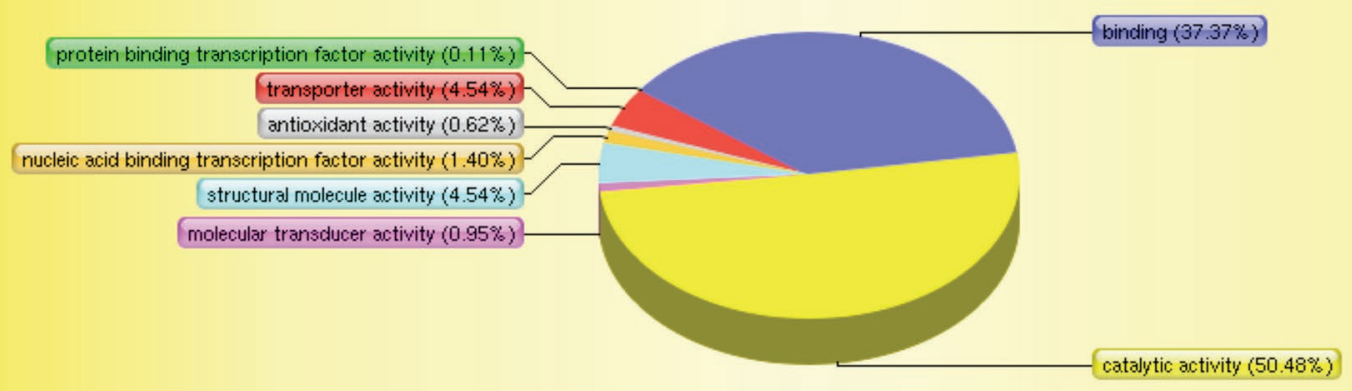

biological process

C

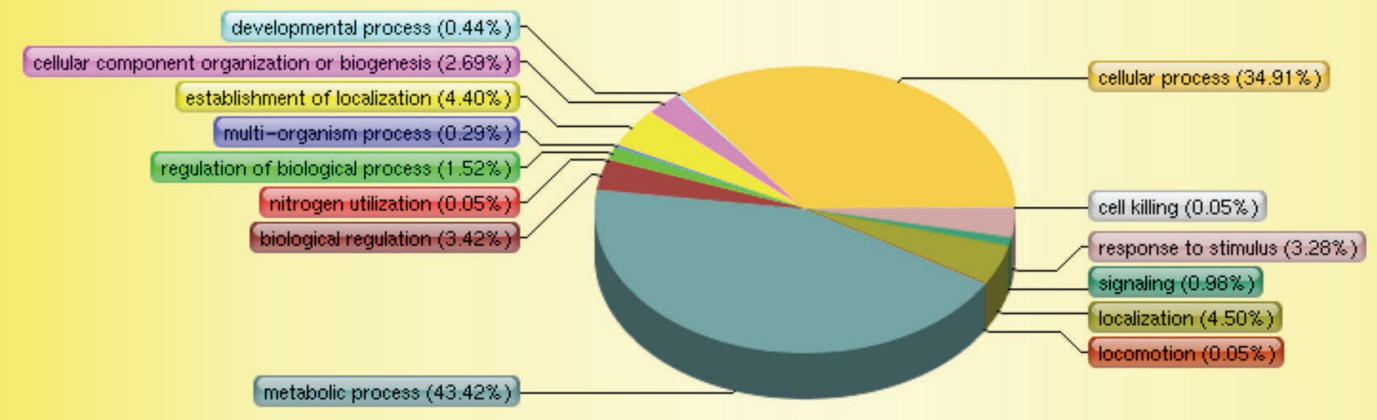

Figure 9. Distribution of the Gene Ontology (GO) terms for differential proteins. The GO classification map represents the percentage of proteins and the distribution of the ontology (A) cellular component, (B) molecular function, and (C) biological process. Color version available online. 
Table 2. Gene function/protein encoded ${ }^{1}$

\begin{tabular}{|c|c|c|c|c|}
\hline Protein & GI & Description & Fold change & E-value \\
\hline B1 (BBIF_0529) & 310287050 & Pyridoxine biosynthesis enzyme & 1.232 & 0 \\
\hline $\mathrm{B} 2(\mathrm{rps})$ & 310288025 & $30 \mathrm{~S}$ ribosomal protein $\mathrm{S} 10$ & 1.264 & $6.00 \mathrm{E}-52$ \\
\hline B4 (BBIF_1401) & 310287922 & Trna [guanine-N(7)-]-methyltransferase & 1.208 & $3.00 \mathrm{E}-175$ \\
\hline $\mathrm{B} 5(\mathrm{rlmN})$ & 421735563 & Ribosomal RNA large subunit methyltransferase N & 1.228 & 0 \\
\hline B6 (rpmC) & 310288016 & 50S ribosomal protein L29 & 2.458 & $1.00 \mathrm{E}-41$ \\
\hline B9 (tuf) & 310287772 & Translation elongation factor $\mathrm{Tu}$ & 1.227 & 0 \\
\hline $\mathrm{B} 10(\mathrm{pdxS})$ & 310286904 & Pyridoxine biosynthesis protein & 2.363 & $2.00 \mathrm{E}-149$ \\
\hline B11 (BBIF_0575) & 310287096 & UDP- $N$-acetylmuramyl tripeptide synthase & 1.281 & $6.00 \mathrm{E}-174$ \\
\hline \multicolumn{5}{|c|}{ Listeria monocytogenes CMCC 54001} \\
\hline tsf & 405758708 & Translation elongation factor Ts (EF-Ts) & 1.297 & $9.00 \mathrm{E}-169$ \\
\hline divIVA & 255016832 & Cell-division initiation protein & 1.55 & $3.00 \mathrm{E}-78$ \\
\hline rpmE2 & 4193373 & Ribosomal protein L31 & 1.531 & $1.00 \mathrm{E}-40$ \\
\hline
\end{tabular}

${ }^{1} \mathrm{GI}=$ Geninfo Identifier; E-value $=$ Expect-value.

further verified that SecA was the anchoring protein of divIVA, helping divIVA locate on the cell membrane (Halbedel et al., 2014). We found that the divIVA of $B$. bifidum WBBI03 and L. monocytogenes CMCC 54001 were quite different, as the molecular weights of the 2 proteins were, respectively, 36 and $26 \mathrm{kDa}$, with a sequence similarity of only $7 \%$. In the National Center for Biotechnology Information database, the sequences of different B. bifidum are essentially the same, with a difference in only $1 \mathrm{AA}$. However, compared with the closest B. longum, the similarity dropped to 73 to $75 \%$. Although the divIVA of $B$. bifidum WBBI03 and $L$. monocytogenes CMCC 54001 were different, their expressions increased during the interactions between the 2 bacteria, implying that it might be closely related to promoting the growth and reproduction of the bacteria.

Two isozymes, pyridoxine biosynthesis enzyme, were found in the differential protein of B. bifidum WBBI03. The product of their synthesis, vitamin $\mathrm{B}_{6}$, is the component of some coenzymes, involved in a variety of metabolic reactions, especially the metabolism of AA. Although the expression of these 2 enzymes was upregulated at the protein levels, on the transcriptional level, Geninfo identifier: 310287050 was downregulated, different from the other differential proteins. It appeared similar to transferrin, which has translational and posttranslational regulation, leading to the contrary levels of transcription and translation. This should be further verified through experiments.

In PBS buffer, the amount of both bacteria did not change during the interactions between $B$. bifidum WBBI03 and L. monocytogenes CMCC 54001, due to

\section{Protein ratio distribution (1_113-VS-2_119)}

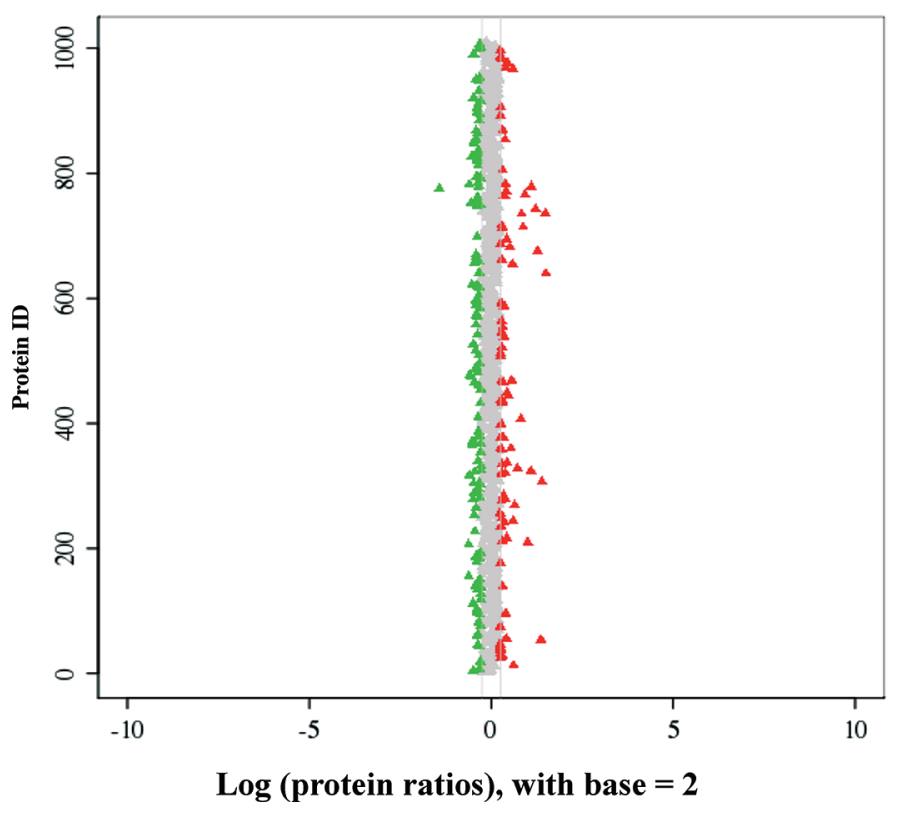

Figure 10. Protein ratio distribution. Ratio $>0$ or $<0$ means up/ downregulated expression (if there is no significant change in the amount of the same protein from 2 samples when the relative quantification was applied, then the ratio is close to 1 in abundance of protein), and the points were marked with black (red) and gray (green) when ratio $>1.2$-fold (black/red for the expression of upregulated; gray/ green for the down expression). These black (red) and gray (green) dots could be differentially expressed proteins, and whether they are eventually screened as differentially expressed proteins also needs to be validated statistically. Color version available online. 
the lack of nutrient elements $\mathrm{C}$ and N. But the transcription and expression of the bacteria changed, and some proteins related to biosynthesis, such as cell division, were found to be accumulated. Later in the culture medium, these proteins with upregulated expressions started to take effect, promoting the growth of the 2 bacteria, resulting in earlier entry into the logarithmic phase. In Kuley et al. (2012) research, they investigated that the role of lactic acid bacteria on biogenic amine production by foodborne pathogens varied depending on strains and specific amine. And phenylethylamine and trimethylamine production by $L$. monocytogenes tended to increase in the presence of lactic acid bacteria strains. Recently, Kernbauer et al. (2014) reported that the norovirus, which causes diarrhea, can promote the reproduction of enterocyte and help recover the intestinal structural and functional injuries due to enteritis. As a typical opportunistic pathogen, L. monocytogenes exists in the intestinal tract of many healthy people (Adzitey and Huda, 2010). So far, the biological significance of its presence has not been reported. We found that $L$. monocytogenes could promote the growth of $B$. bifidum, a representative of probiotics. This implied that the opportunistic pathogens existing in the gastrointestinal tract of healthy people might also have such symbiosis with the intestinal probiotics, promoting the growth and reproduction of probiotics and enhancing its prebiotic effects. This study verified that the other 3 foodborne opportunistic pathogens could also promote the growth of other probiotics, but more opportunistic pathogens and probiotics should be selected in further studies to detect this growth-promoting effect and to more clearly explain its molecular mechanism, in an attempt to provide sufficient data support for revealing the biological significance of the presence of opportunistic pathogens.
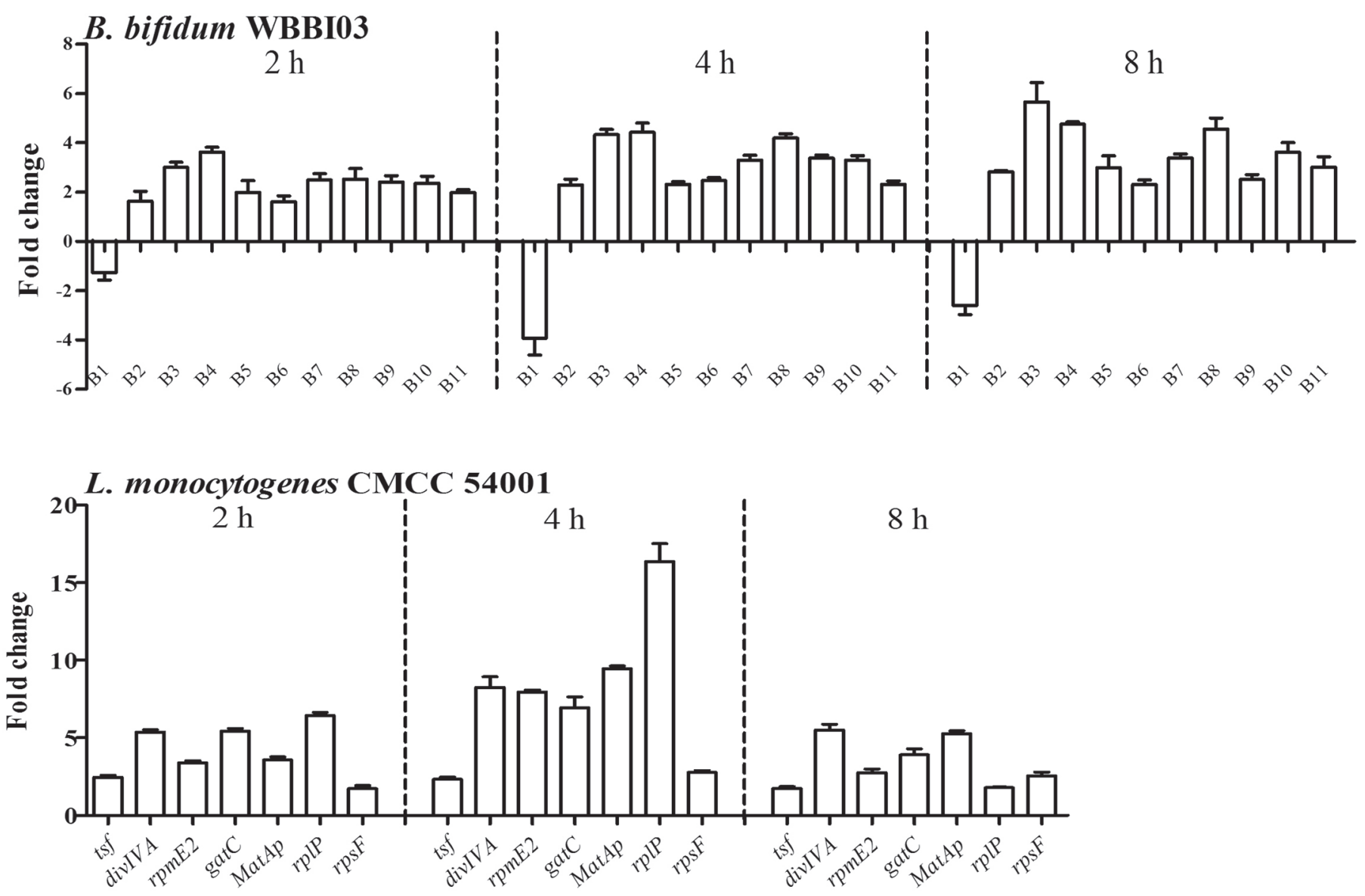

Figure 11. Relative gene transcriptional levels between the co-incubation group and the individual-incubation group of Bifidobacterium bifidum WBBI03 and Listeria monocytogenes CMCC 54001 after incubating in PBS for 2, 4, and 8 h. B1 to B11 are genes of B. bifidum WBBI03. Detailed information about genes is given in Table 2. Transcripts of the relative genes were quantified by real-time quantitative PCR. Data were analyzed by using the comparative critical threshold $2^{-\Delta \Delta \mathrm{CT}}$ method. A ratio greater than zero indicated upregulation of gene expression. Data are presented as the mean values, and the error bars represent the standard deviations of triplicates. 

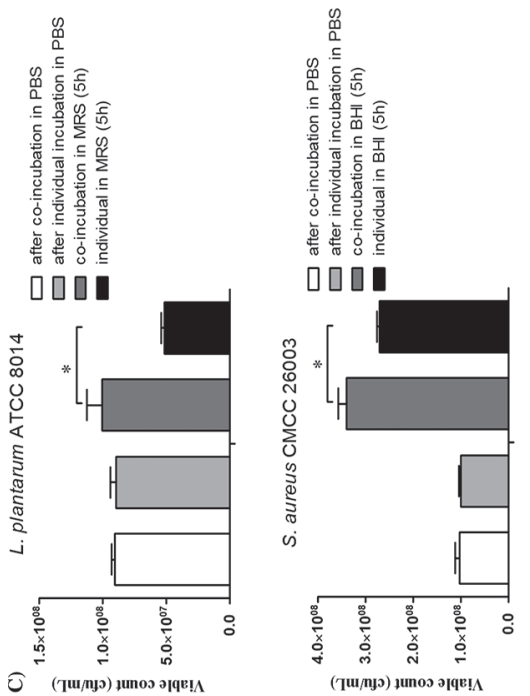



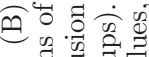

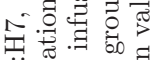

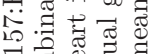

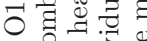

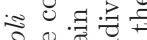

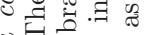

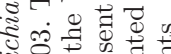

○。

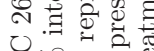

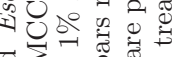

리유

के

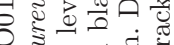

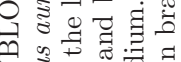

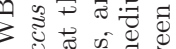

ह

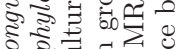

ह क 0.0 .7 .0$.

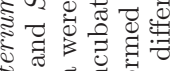
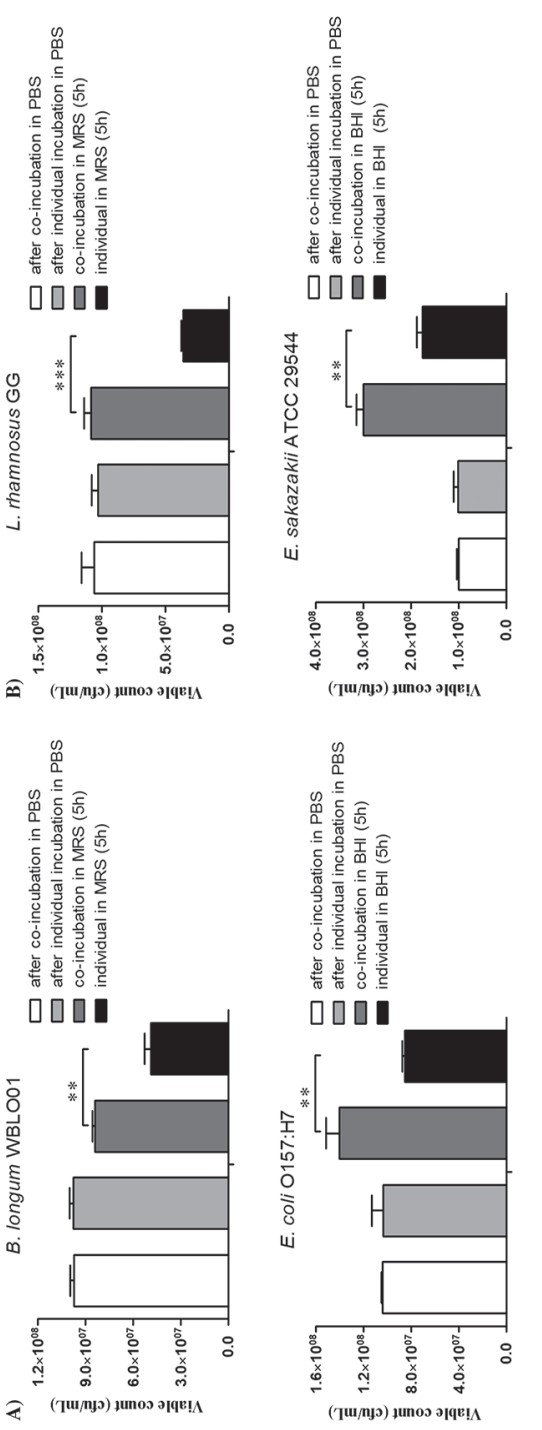

$\forall$.

\section{ACKNOWLEDGMENTS}

This work was supported by the National Natural Science Foundation of China (NSF31170091, 31360377, 31260363, 81160494, 31000048), Chinese High-Tech R\&D (863) Program (2014AA022209), and Ganpo Talent 555 Engineering Project of Jiangxi Province (China).

\section{REFERENCES}

Adzitey, F., and N. Huda. 2010. Listeria monocytogenes in foods: Incidences and possible control measures. Afr. J. Microbiol. Res. $4: 2848-2855$

Allerberger, F., and M. Wagner. 2010. Listeriosis: A resurgent foodborne infection. Clin. Microbiol. Infect. 16:16-23.

Bernet, M.-F., D. Brassart, J.-R. Neeser, and A. Servin. 1993. Adhesion of human bifidobacterial strains to cultured human intestinal epithelial cells and inhibition of enteropathogen-cell interactions. Appl. Environ. Microbiol. 59:4121-4128.

Braden, C. R., and R. V. Tauxe. 2013. Emerging trends in foodborne diseases. Infect. Dis. Clin. North Am. 27:517-533.

Chiang, Y.-C., H.-Y. Tsen, H.-Y. Chen, Y.-H. Chang, C.-K. Lin, C.Y. Chen, and W.-Y. Pai. 2012. Multiplex PCR and a chromogenic DNA macroarray for the detection of Listeria monocytogens, Staphylococcus aureus, Streptococcus agalactiae, Enterobacter sakazakii, Escherichia coli O157:H7, Vibrio parahaemolyticus, Salmonella spp. and Pseudomonas fluorescens in milk and meat samples. J. Microbiol. Methods 88:110-116.

Claeys, W. L., S. Cardoen, G. Daube, J. De Block, K. Dewettinck, K. Dierick, L. De Zutter, A. Huyghebaert, H. Imberechts, and P. Thiange. 2013. Raw or heated cow milk consumption: Review of risks and benefits. Food Contr. 31:251-262.

Derrien, M., and J. E. van Hylckama Vlieg. 2015. Fate, activity, and impact of ingested bacteria within the human gut microbiota. Trends Microbiol. 23:354-366.

Dethlefsen, L., M. McFall-Ngai, and D. A. Relman. 2007. An ecological and evolutionary perspective on human-microbe mutualism and disease. Nature 449:811-818.

Dobranić, V., S. Kazazić, I. Filipović, and N. Zdolec. 2015. Identification of Enterococci from raw cow milk by MALDI-TOF MS. In Proc. Book of Abstracts the International Congress "Veterinary Science and Profession." Horvatek Tomić, Danijela; Severin, Krešimir; Slavica, Alen.

Eckburg, P. B., E. M. Bik, C. N. Bernstein, E. Purdom, L. Dethlefsen, M. Sargent, S. R. Gill, K. E. Nelson, and D. A. Relman. 2005. Diversity of the human intestinal microbial flora. Science 308:1635-1638.

Feehily, C., C. P. O'Byrne, and K. A. G. Karatzas. 2013. Functional $\gamma$-aminobutyrate shunt in Listeria monocytogenes: Role in acid tolerance and succinate biosynthesis. Appl. Environ. Microbiol. 79:74-80.

Gagnon, M., A. Zihler, C. Chassard, and C. Lacroix. 2011. Ecology of probiotics and enteric protection. Pages $65-85$ in Probiotic Bacteria and Enteric Infections. Springer, Dordrecht, the Netherlands.

Gaillard, J. L., P. Berche, C. Frehel, E. Gouin, and P. Cossart. 1991 Entry of L. monocytogenes into cells is mediated by internalin, a repeat protein reminiscent of surface antigens from gram-positive cocci. Cell 65:1127-1141.

Gibson, G. R., and X. Wang. 1994. Regulatory effects of bifidobacteria on the growth of other colonic bacteria. J. Appl. Bacteriol. $77: 412-420$.

Grif, K., G. Patscheider, M. Dierich, and F. Allerberger. 2003. Incidence of fecal carriage of Listeria monocytogenes in three healthy volunteers: A one-year prospective stool survey. Eur. J. Clin. Microbiol. Infect. Dis. 22:16-20. 
Halbedel, S., B. Hahn, R. A. Daniel, and A. Flieger. 2012. DivIVA affects secretion of virulence-related autolysins in Listeria monocytogenes. Mol. Microbiol. 83:821-839.

Halbedel, S., M. Kawai, R. Breitling, and L. W. Hamoen. 2014. SecA is required for membrane targeting of the cell division protein DivIVA in vivo. Front. Microbiol. 5:58

Hald, T., W. Aspinall, B. Devleesschauwer, R. Cooke, T. Corrigan, A. H. Havelaar, H. J. Gibb, P. R. Torgerson, M. D. Kirk, and F. J. Angulo. 2016. World Health Organization estimates of the relative contributions of food to the burden of disease due to selected foodborne hazards: A structured expert elicitation. PLoS One 11:e0145839.

Kernbauer, E., Y. Ding, and K. Cadwell. 2014. An enteric virus can replace the beneficial function of commensal bacteria. Nature 516:94-98.

Kuley, E., E. Balıkcı, İ. Özoğul, S. Gökdogan, and F. Özoğul. 2012. Stimulation of cadaverine production by foodborne pathogens in the presence of Lactobacillus, Lactococcus, and Streptococcus spp. J. Food Sci. 77:M650-M658.

Le Loir, Y., F. Baron, and M. Gautier. 2003. Staphylococcus aureus and food poisoning. Genet. Mol. Res. 2:63-76.

Lee, J. W., E. H. Kim, I. B. Yim, and H. G. Joo. 2004. Immunomodulatory and antitumor effects in vivo by the cytoplasmic fraction of Lactobacillus casei and Bifidobacterium longum. J. Vet. Sci. 5:41-48.

Li, F., and L. Zhang. 2006. Study on processing of functional milk drink with Grifola frondosus fermented by Bifidobacteria. Food Sci. 10:362-365.

Liévin-Le Moal, V., and A. L. Servin. 2014. Anti-infective activities of lactobacillus strains in the human intestinal microbiota: From probiotics to gastrointestinal anti-infectious biotherapeutic agents. Clin. Microbiol. Rev. 27:167-199.

Macfarlane, G. T., and J. H. Cummings. 1999. Probiotics and prebiotics: Can regulating the activities of intestinal bacteria benefit health? BMJ 318:999-1003.

Manges, A. R., and J. R. Johnson. 2012. Foodborne origins of Escherichia coli causing extraintestinal infections. Clin. Infect. Dis. 55:712-719.

Martín, R., S. Miquel, J. Ulmer, P. Langella, and L. Bermudez-Humaran. 2014. Gut ecosystem: How microbes help us. Benef. Microbes $5: 219-233$.

Medici, M., C. G. Vinderola, and G. Perdigón. 2004. Gut mucosal immunomodulation by probiotic fresh cheese. Int. Dairy J. 14:611618.

Mérault, N., C. Rusniok, S. Jarraud, L. Gomez-Valero, C. Cazalet, M. Marin, E. Brachet, P. Aegerter, J. Gaillard, and J. Etienne. 2011. Specific real-time PCR for simultaneous detection and identification of Legionella pneumophila serogroup 1 in water and clinical samples. Appl. Environ. Microbiol. 77:1708-1717.

Minelli, E. B., A. Benini, L. Vicentini, E. Andreoli, M. Oselladore, and R. Cerutti. 2009. Effect of Lactobacillus acidophilus and Bi- fidobacterium bifidum administration on colonic microbiota and its metabolic activity in premenstrual syndrome. Microb. Ecol. Health Dis. 9:247-260.

Oliver, S. P., B. M. Jayarao, and R. A. Almeida. 2005. Foodborne pathogens in milk and the dairy farm environment: food safety and public health implications. Foodborne Pathog. Dis. 2:115-129.

Park, S.-H., P.-S. Chang, S. Ryu, and D.-H. Kang. 2014. Development of a novel selective and differential medium for the isolation of Listeria monocytogenes. Appl. Environ. Microbiol. 80:1020-1025.

Peng, M., G. Reichmann, and D. Biswas. 2015. Lactobacillus casei and its byproducts alter the virulence factors of foodborne bacterial pathogens. J. Funct. Foods 15:418-428.

Salminen, S., S. Nybom, J. Meriluoto, M. C. Collado, S. Vesterlund, and H. El-Nezami. 2010. Interaction of probiotics and pathogensBenefits to human health? Curr. Opin. Biotechnol. 21:157-167.

Schell, M. A., M. Karmirantzou, B. Snel, D. Vilanova, B. Berger, G. Pessi, M.-C. Zwahlen, F. Desiere, P. Bork, and M. Delley. 2002. The genome sequence of Bifidobacterium longum reflects its adaptation to the human gastrointestinal tract. Proc. Natl. Acad. Sci. USA 99:14422-14427.

Servin, A. L., and M.-H. Coconnier. 2003. Adhesion of probiotic strains to the intestinal mucosa and interaction with pathogens. Best Pract. Res. Clin. Gastroenterol. 17:741-754.

Sim, J., D. Hood, L. Finnie, M. Wilson, C. Graham, M. Brett, and J. Hudson. 2002. Series of incidents of Listeria monocytogenes noninvasive febrile gastroenteritis involving ready-to-eat meats. Lett. Appl. Microbiol. 35:409-413.

Tan, Q., H. Xu, T. Chen, P. Li, Z. P. Aguilar, D. Xu, X. Ming, F. $\mathrm{Xu}$, and H. Wei. 2012. Differential expression of virulence and stress fitness genes during interaction between Listeria monocytogenes and Bifidobacterium longum. Biosci. Biotechnol. Biochem. 76:699-704.

Vinderola, C., and J. Reinheimer. 1999. Culture media for the enumeration of Bifidobacterium bifidum and Lactobacillus acidophilus in the presence of yoghurt bacteria. Int. Dairy J. 9:497-505.

$\mathrm{Xu}$, R., N. Shang, and P. Li. 2011. In vitro and in vivo antioxidant activity of exopolysaccharide fractions from Bifidobacterium animalis RH. Anaerobe 17:226-231.

Yang, Y., F. Xu, H. Xu, Z. P. Aguilar, R. Niu, Y. Yuan, J. Sun, X. You, W. Lai, and Y. Xiong. 2013. Magnetic nano-beads based separation combined with propidium monoazide treatment and multiplex PCR assay for simultaneous detection of viable Salmonella typhimurium, Escherichia coli $\mathrm{O} 157: \mathrm{H} 7$ and Listeria monocytogenes in food products. Food Microbiol. 34:418-424.

Zarei, M., S. Maktabi, and M. Ghorbanpour. 2012. Prevalence of Listeria monocytogenes, Vibrio parahaemolyticus, Staphylococcus aureus, and Salmonella spp. in seafood products using multiplex polymerase chain reaction. Foodborne Pathog. Dis. 9:108-112. 